\title{
Splenic vein graft for the reconstruction of the mesenteric-portal trunk after gastroduodenopancreatectomy
}

\section{Enxerto de veia esplênica na reconstrução do eixo mesentérico-portal após gastroduodenopancreatectomia}

\author{
Enio Campos Amico'; José Roberto Alvesi Samir Assi João
}

\begin{abstract}
A B S T R A C T
Resection of the confluence of the superior mesenteric and portal veins has been performed most frequently in the treatment of adenocarcinoma of the pancreas, in view of the reported positive results, but it can also be used in cases of benign pancreatic neolpasias when they are strongly adhered to the mesenteric-portal trunk. Nevertheless, there is no study on the best type of venous grafts for reconstruction of the mesenteric-portal trunk when required. The choice of graft depends on the preference of the surgeon or the institution. This technical note critically discusses the use of the splenic vein as an option for mesenteric-portal trunk reconstruction after gastroduodenopancreatectomy.
\end{abstract}

Key words: Pancreaticoduodenectomy. Vascular grafting. Splenic vein. Pancreatic neoplasms.

\section{INTRODUCTION}

$\mathrm{D}$ ue to its anatomical proximity to the pancreas, the mesenteric-portal axis (MPA) is often affected by pancreatic tumors. For patients with pancreatic adenocarcinoma, resection of the MPA has been recommended, which allows tumor resection with free margins. For other types of pancreatic tumors with better prognosis, particularly the benign, resection of the MPA when invaded by the tumor seems the most obvious indication. Resection of MPA should always be attempted, since the possibility of cure for these tumors is high when completely resected.

Despite its applicability, however, there is no comparative study available in the literature to evaluate the best type of graft to be used in the reconstruction of venous MPA when primary anastomosis of the vascular stumps is not possible. This technical note critically discusses the use of a splenic vein graft for reconstruction of the MPA after gastroduodenopancreatectomy by Frantz tumor.

\section{TECHNIQUE}

Through laparotomy, before the venous resection of MPA, the uncinate process is completely released from the superior mesenteric vein. Both the anterior dissection (sometimes hampered by adherence of the tumor to the vein) and the posterior were necessary. The objective is to reduce the time of clamping, since the specimen, already completely released after the venous clamping and resection, is readily removed from the surgical field.

The segment and length of the vein to be resected are identified based on the location of tumor involvement. In the present case there was involvement of the superior mesenteric and portal veins, in a length of $6 \mathrm{~cm}$. We then opted for the use of splenic vein graft.

The procedure consisted of the following steps: 1) Ligation of the splenic artery near the splenic hilum; 2) Infusion "bolus" of 5000 IU of heparin intravenously before clamping; 3) clamping of the portal and superior mesenteric veins $2 \mathrm{~cm}$ far from the site of resection. Clamping of the splenic vein at the emergence of the MPA; 4) Resection of the surgical specimen (resulting from the gastroduodenopancreatectomy); 5) Harvesting of the splenic vein segment through ligation of the tributaries of the pancreatic parenchyma; 6 ) splenic vein graft interposition between the stump of the portal vein and superior mesenteric vein through anastomoses with continuous sutures in a single plane of 6.0 polypropylene suture (Figure $1 A$ and $B$ ). Completion of the continuous suture leaving up a "growth factor". Note that the reconstruction of the MPA with splenic vein graft presents in anatomic form after the anastomoses (Figure 2); and 7) Total splenectomy and hemostasis review.

1. Universidade Federal do Rio Grande do Norte (UFRN), Natal, Rio Grande do Norte State - RN, Brazil. 


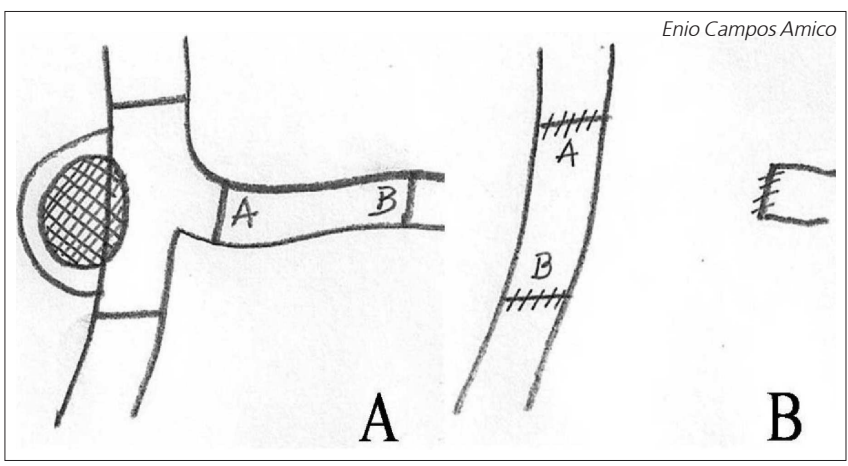

Figure 1 - A) Illustration showing tumor involvement of the mesenteric-portal axis (MPA); B) Illustration showing the MPA reconstruction through splenic vein grafting.

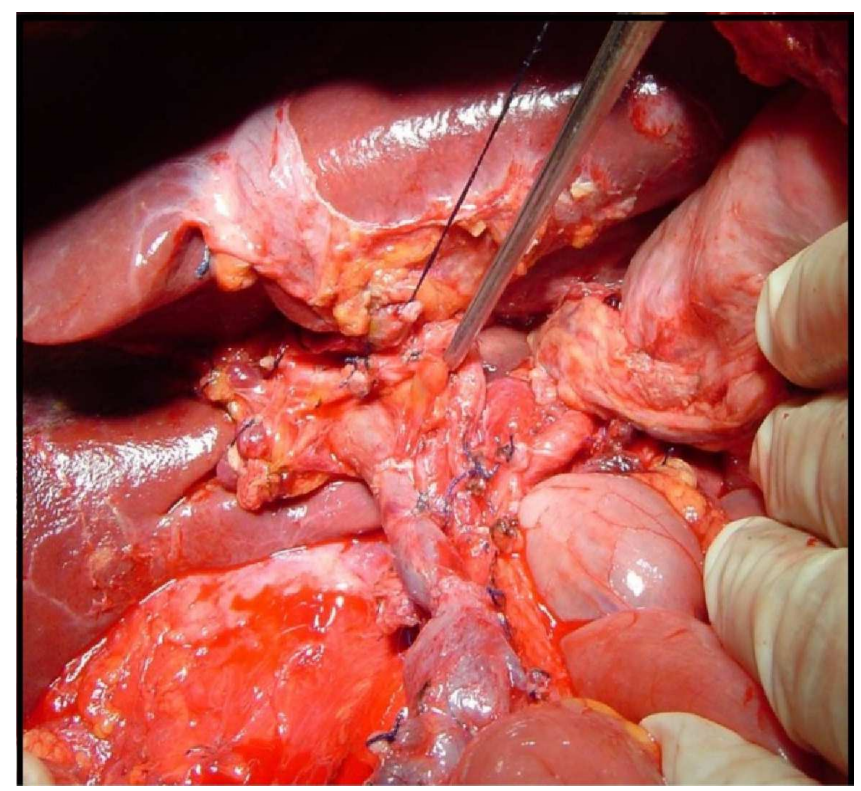

Figure 2 - Final aspect of the mesenteric-portal axis (MPA) after reconstruction with autologous splenic vein.

\section{DISCUSSION}

Primary anastomosis is the simplest and most accomplished method after resection of $\mathrm{MPA}^{1}$. In an extensive literature review that included case series of pancreatectomy with resection of the MPA, Siriwardana et al. observed that primary anastomosis was performed in $88.6 \%$ of patients with venous circumferential resection ${ }^{2}$. Zhang et al. have reported good results in eight patients with large primary repairs after MPA venous resection (> $5 \mathrm{~cm})^{3}$. A short period of visceral congestion, associated with a single suture line and proportional size of the anastomotic rings make the method preferable to any other ${ }^{3}$.

When primary repair is impossible, graft interposition of autologous or cadaveric vein, or prosthesis, is imperative ${ }^{1}$. The mostly used surrogate is the internal jugular vein, for it has adequate caliber in most cases and it does not cause venous insufficiency in cervical segment once resected, and to prevent portal hypertension'. A disadvantage of its use is the existence of limited access to the neck by another surgical team, invariably the case in such patients, for whom multiple monitoring lines are the rule.

The risk of thrombosis related to the use of cadaveric vein grafts (iliac vein) should be stressed, and the onset of infection and pancreatic fistula related to the use of polytetrafluoroethylene prostheses ${ }^{1}$.

The description of the use of the splenic vein in the reconstruction of MPA is old. Miyata et al. applied the technique in three patients with pancreatic cancer ${ }^{4}$. The advantages of using the splenic vein are convenience, rapidity and better exposure of the superior mesenteric artery ${ }^{4}$. The practicality lies in the lack of need for the presence of another team to harvest the graft. The speed is due to the use of a single surgical field, associated with the proximity of the splenic vein to the portal vein, as well as being already virtually dissected by the mobilization of the pancreas. In addition, there is the opportunity to more adequately expose the medial edge of the superior mesenteric artery, considered a critical region to obtain a negative margin in the cephalic pancreatectomy.

The main indication for the use of splenic vein graft reconstruction of the MPA is pancreatic adenocarcinoma. One should consider a short mean survival time for these patients ${ }^{4}$, probably being less than that required for the development of gastric varices with clinical repercussion. In our view, for cases of advanced pancreatic adenocarcinoma, the use of the splenic vein grafts may be indicated in cases in which it uses the segment between the portal vein and the inferior mesenteric vein. Anyway, the prophylactic ligation of the short gastric vessels and the left gastroepiploic vein seems reasonable in these cases, adding little regarding operative time, but preventing the onset of hypertension of the portal system.

In cases of less aggressive tumors, with expected prolonged survival, we believe that another graft, such as the internal jugular vein, preserving and maintaining the flow of the splenic vein, may give better results in the long term. The splenic vein grafts, however, can be used associated with splenectomy to help prevent hypertension of the portal system.

Splenectomy prevents the development of collateral vessels, being the recommended treatment for segmental venous hypertension in cases of splenic vein thrombosis. In this scenario, however, the concern is the risk of post-splenectomy sepsis. Some aspects, nonetheless, can minimize such concerns, making use of the splenic vein graft possible, with minimal risk: 1) The risk of post-splenectomy sepsis is higher in children in the first two years postoperatively; 2 ) The risk that was initially considered of $4.25 \%$ to be less than $1 \%$ in more recent studies seem; 3) Post-splenectomy sepsis can be prevented through measures that include vaccination and the use of antibiotics ${ }^{5}$. 
We conclude that the use of the splenic vein graft reconstruction of MPA after resection of pancreatic tumors is a practical alternative and may be considered as a technical alternative to other available venous grafts.

\title{
R E S U M O
}

\begin{abstract}
A ressecção da confluência das veias mesentérica superior e porta tem sido realizada com maior frequência no tratamento de adenocarcinoma do pâncreas, em virtude dos bons resultados relatados, porém pode também ser usada em casos de neoplasias pancreáticas benignas quando firmemente aderidas ao eixo mesentérico-portal. Apesar disso, não existe nenhum estudo sobre o melhor tipo de enxerto venoso para reconstrução do eixo mesentérico-portal quando necessária. A escolha do enxerto dependerá da preferência do cirurgião ou da instituição onde ocorre à cirurgia. Esta nota técnica discute criticamente o uso da veia esplênica como opção para reconstrução do eixo mesentérico-portal após gastroduodenopancreatectomia.
\end{abstract}

Descritores: Pancreaticoduodenectomia. Enxerto vascular. Veia esplênica. Neoplasias pancreáticas.

\section{REFERENCES}

1. Marangoni G, O'Sulivan A, Faray W, Heaton N, Rela M Pancreatectomy with synchronous vascular resection-an argment in favour. Surgeon. 2012;10(2):102-6.

2. Siriwardana HP, Siriwardena AK. Systematic review of outcome of synchronous portal-superior mesenteric vein resection during pancreatectomy for cancer. Br J Surg. 2006;93(6):662-73.

3. Zhang J, Qian HG, Leng JH, Cui M, Qiu H, Zhou GQ, et al. Long mesentericoportal vein resection and end-to-end anastomosis without graft in pancreaticoduodenectomy. J Gastrointest Surg. 2009;13(8):1524-8.

4. Miyata M, Nakao K, Hirose $H$, Hamaji M, Kawashima $Y$. Reconstruction of portal vein with an autograft of splenic vein. J Cardiovasc Surg. 1987;28(1):18-21.
5. Melles DC, de Marie S. Prevention of infections in hyposplenic and asplenic patients: an update. Neth J Med. 2004;62(2):45-52.

Received on 20/08/2013

Accepted for publication 15/11/2013

Conflict of interest: none.

Source of funding: none.

Mailing address:

Enio Campos Amico

E-mail: ecamic@uol.com.br 